\title{
Climate-crop yield relationships at provincial scales in China and the impacts of recent climate trends
}

\author{
Fulu Tao ${ }^{1, *}$, Masayuki Yokozawa ${ }^{2}$, Jiyuan Liu ${ }^{1}$, Zhao Zhang ${ }^{3}$ \\ ${ }^{1}$ Institute of Geographical Sciences and Natural Resources Research, Chinese Academy of Sciences, Beijing 100101, China \\ ${ }^{2}$ National Institute for Agro-Environmental Sciences, 3-1-3 Kannondai, Tsukuba, Ibaraki 305-8604, Japan \\ ${ }^{3}$ State Key Laboratory of Earth Surface Processes and Resource Ecology, Beijing Normal University, Beijing 100875, China
}

\begin{abstract}
Understanding climate-yield relationships and the impacts of recent climate trends on crop productivity on a large scale is an important step in predicting regional agricultural production. In this study we investigated climate-crop relationships, recent trends in seasonal climate (maximum and minimum temperatures, diurnal temperature range and precipitation) and their impacts on the yields of major crops (i.e. rice, wheat, maize and soybean) at provincial scales throughout China over the last few decades. We found that major crop yields were significantly related to growing season climate in the main production regions of China, and that growing season temperature had a generally significant warming trend. Due to the trends in growing season climate, total rice production in China was estimated to have increased by $3.2 \times 10^{5} \mathrm{t} \mathrm{decade}^{-1}$ during the period $1951-2002$; total production of wheat, maize and soybean changed by $-1.2 \times 10^{5},-21.2 \times 10^{5}$ and $0.7 \times 10^{5}$ t decade $^{-1}$, respectively, during 1979-2002. The warming trend increased rice yield in northeast China and soybean in north and northeast China; however, it decreased maize yield in 7 provinces (autonomous region or municipality) and wheat yield in 3 provinces. Our analysis presents the general response patterns of regional agricultural productivity to seasonal climate variability and change over the last few decades. Crop response mechanisms to local seasonal climate change (and variability) need further investigation to better understand the patterns and predict future consequences of climate change and variability on regional agricultural production.
\end{abstract}

KEY WORDS: Agriculture $\cdot$ China $\cdot$ Climate change $\cdot$ Food security $\cdot$ Impacts $\cdot$ Yield variability Resale or republication not permitted without written consent of the publisher

\section{INTRODUCTION}

The potential impacts of future climate change on regional agricultural production have attracted considerable attention. Extensive studies have projected the potential impacts of future climate change on agricultural productivity by driving crop models (process-based or statistical) with global climate model outputs (e.g. Rosenzweig \& Parry 1994, Tao et al. 2008). To evaluate future climate impacts on crop productivity, the impacts of climate over the past few decades need to be assessed (Nicholls 1997). Climate-yield relationships are quite complex; nevertheless, robust relationships can be established between regional atmospheric circulation, surface climate and crop productivity (e.g. Iglesias \& Quiroga 2007, Jones \& Goodrich 2008). Climate- yield relationships are also scale-dependent. While detailed records on crop performance and weather at observation stations are valuable for investigating crop response mechanisms to weather (e.g. Peng et al. 2004, Tao et al. 2006), large-scale statistical data and regional climate datasets are important for investigating general response patterns of crop production to climate change and variability (e.g. Lobell 2007, Lobell et al. 2008).

Spatial patterns of seasonal climate and their impacts on crop productivity at provincial or regional scales are important for understanding vulnerability and adaptation of regional agricultural production to climate change. Here, we systematically investigate climateyield relationships and the impacts of climate trends over the last few decades on major crop yields at provincial scales throughout China in a spatially explicit way. 


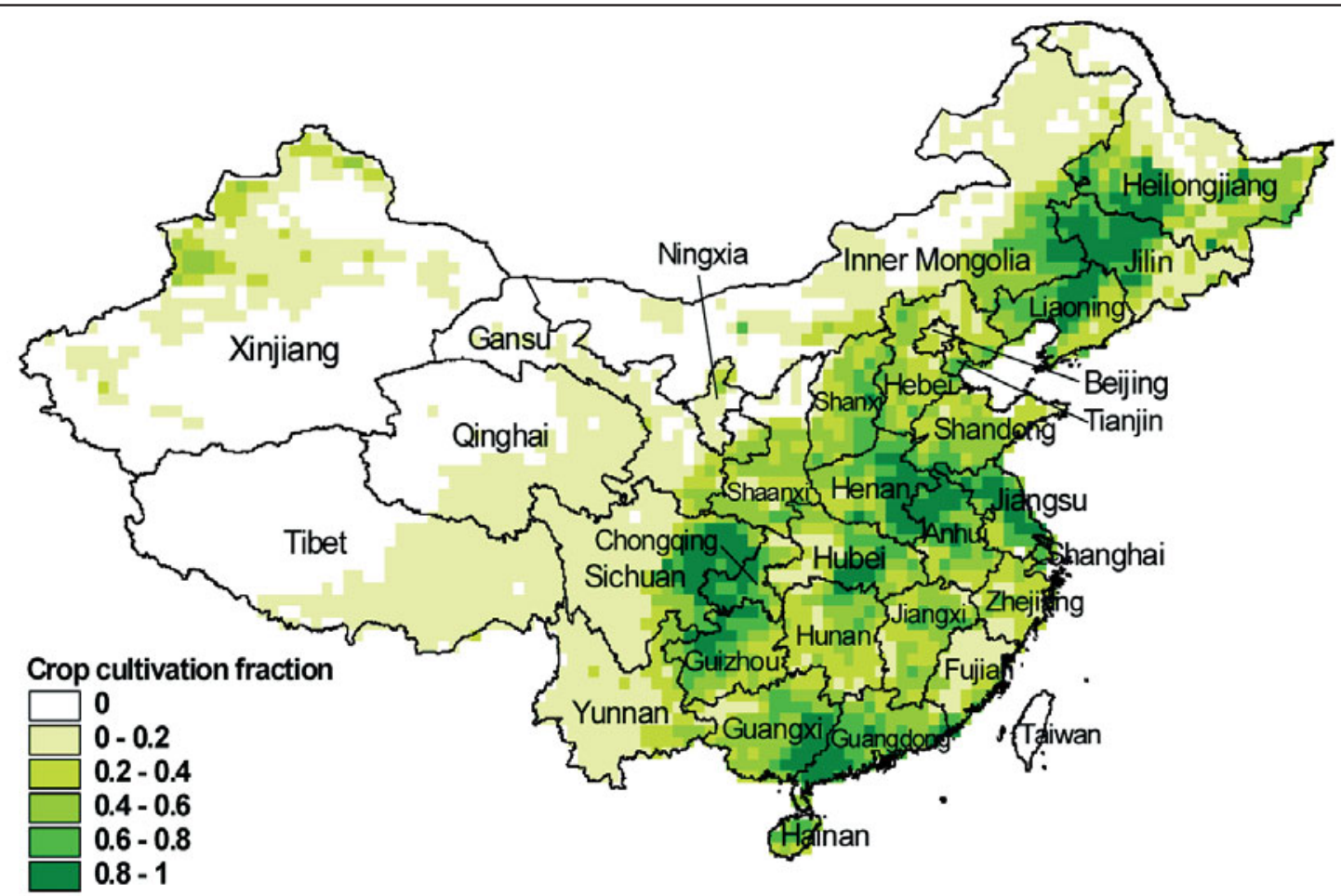

Fig. 1. Crop cultivation fraction and provinces (autonomous region or municipality) in China, around 2000

\section{DATA AND METHODS}

Areas sown (Fig. 1) to wheat, maize and soybean by province in China from 1979 to 2002 and time series of yields were obtained from the China Agricultural Yearbook (China Agriculture Press, Beijing 1980-2003 [annual]). For rice, such data from 1950 to 2002 were obtained from the world rice statistics of the International Rice Research Institute (IRRI), sources of which were the China Agricultural Yearbook, the Rice Economy Database of China National Rice Institute (unpublished database, National Rice Research Institute, Hangzhou, China) (for the period 1950-1985), 50 Years Rural Statistics of New China (China Statistics Press, Beijing, 1999) and the China Rural Statistics Yearbook 2001-2005 (China Statistics Press, Beijing, 2002-2006) (for the period 1986-2004).

Monthly fields of maximum temperature $\left(T_{\mathrm{m}}\right)$, minimum temperature $\left(T_{\mathrm{n}}\right)$, diurnal temperature range (DTR) and precipitation (Pre) on $0.5^{\circ}$ grids for 1979 to 2002 were obtained from the Climatic Research Unit (CRU, University of East Anglia, UK), Dataset CRU TS 2.1 (Mitchell \& Jones 2005). Spatially weighted averages of the CRU data were computed for each crop and each province (autonomous region or municipality), with weights defined by the spatial distribution of crop area on $0.5^{\circ}$ grids from Frolking et al. (2002) and Qiu et al. (2002), resulting in crop-specific monthly time series of $T_{\mathrm{m}}, T_{\mathrm{n}}, \mathrm{DTR}$ and Pre by province.

Typical cropping system, planting date and growing season (exact to month) for each crop in each province were obtained from historical records (Tao et al. 2006) and CCSA (1989). For each crop in a province, we assumed a similar growing season throughout the study period because the phenology shift due to weather, climate trend or farm management was generally $<1$ mo over the period (Tao et al. 2006). For the cropping system of double rice, the growing season was defined to cover the growing period of both early and late rice. We further computed the average of each climate variable during the crop growing season by province.

To investigate the climate-yield relationship by province, we used a common approach (Nicholls 1997, Lobell \& Field 2007) based on the first-difference time series for yield ( $\Delta$ Yield) and climate (i.e. year to year changes) $\left(\Delta T_{\mathrm{m}}, \Delta T_{\mathrm{n}}, \Delta \mathrm{DTR}\right.$ and $\Delta$ Pre). This approach avoids the confounding influence of long-term variations such as changes in crop management. The relationships between $\Delta$ Yield and $\Delta T_{\mathrm{m}}, \Delta T_{\mathrm{n}}, \Delta \mathrm{DTR}$ and $\Delta$ Pre were evaluated using Pearson correlation analyses. Due to the limited historical sample size, a bootstrap resampling approach was used to estimate the sampling uncertainty associated with the derived 

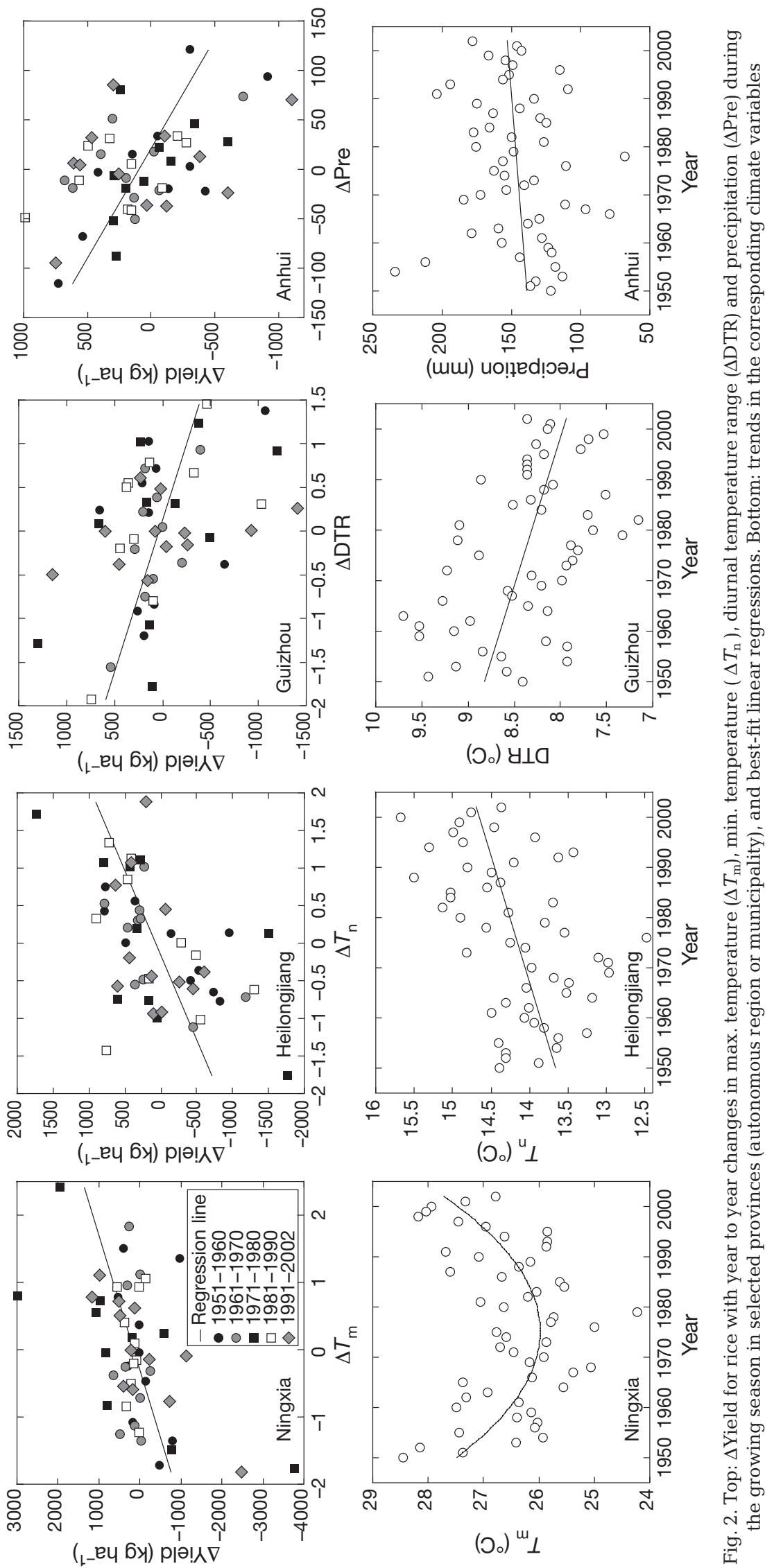

regression coefficients. Specifically, the original data was resampled with replacement, a new regression model was computed, and this was repeated 1000×. The simple linear regression allows identification of the most relevant climate parameter for each crop and province. We also conducted multiple linear regressions (MUL), with $\Delta$ Yield as the dependent variable, and $\Delta$ Pre, 2 variables of $\Delta T_{\mathrm{m}}$ and $\Delta T_{\mathrm{n}}$, and $\Delta \mathrm{DTR}$ (decided by the stepping criteria for entry and removal while regressing) as independent variables.

We also investigated the time trends of changes in the climate variables by regression and Kendall's tau statistic. Statistical significance was tested using 2 -tailed $t$-test. Finally, we applied the regression models to observed trends in climate variables to estimate the role of climate in recent yield trends, which, together with the areas sown to each crop in 2002, were further used to estimate the total crop production change for the whole of China (weighted by sown area).

\section{RESULTS}

\subsection{Climate-yield relationship at the provincial scale}

\subsubsection{Rice}

Among the 23 major provinces that produce rice throughout China; northeast China including Heilongjiang (Fig. 2), Jilin and Liaoning provinces, and Ningxia autonomous region in north China, showed significant positive correlation $(\mathrm{p}<0.01)$ between rice yield and growing season $T_{\mathrm{m}}$ and $T_{\mathrm{n}}$ (Fig. 3). Growing season $T_{\mathrm{m}}$ was also positively correlated to rice yield in Shanghai $(p<0.05)$, but negatively related to rice yield in Guizhou province in south China ( $p<0.05)$. The crop-climate relationship did not appear to change through time. Compared with the yield in 2002, rice yield decreased by 1.3 to $5.8 \%$ in Guizhou for each degree increase in growing season $T_{\mathrm{m}}$. In contrast, it increased by 3.1 to $9.0 \%$ in Ningxia (Fig. 3). Up to $27 \%$ of the variance in 

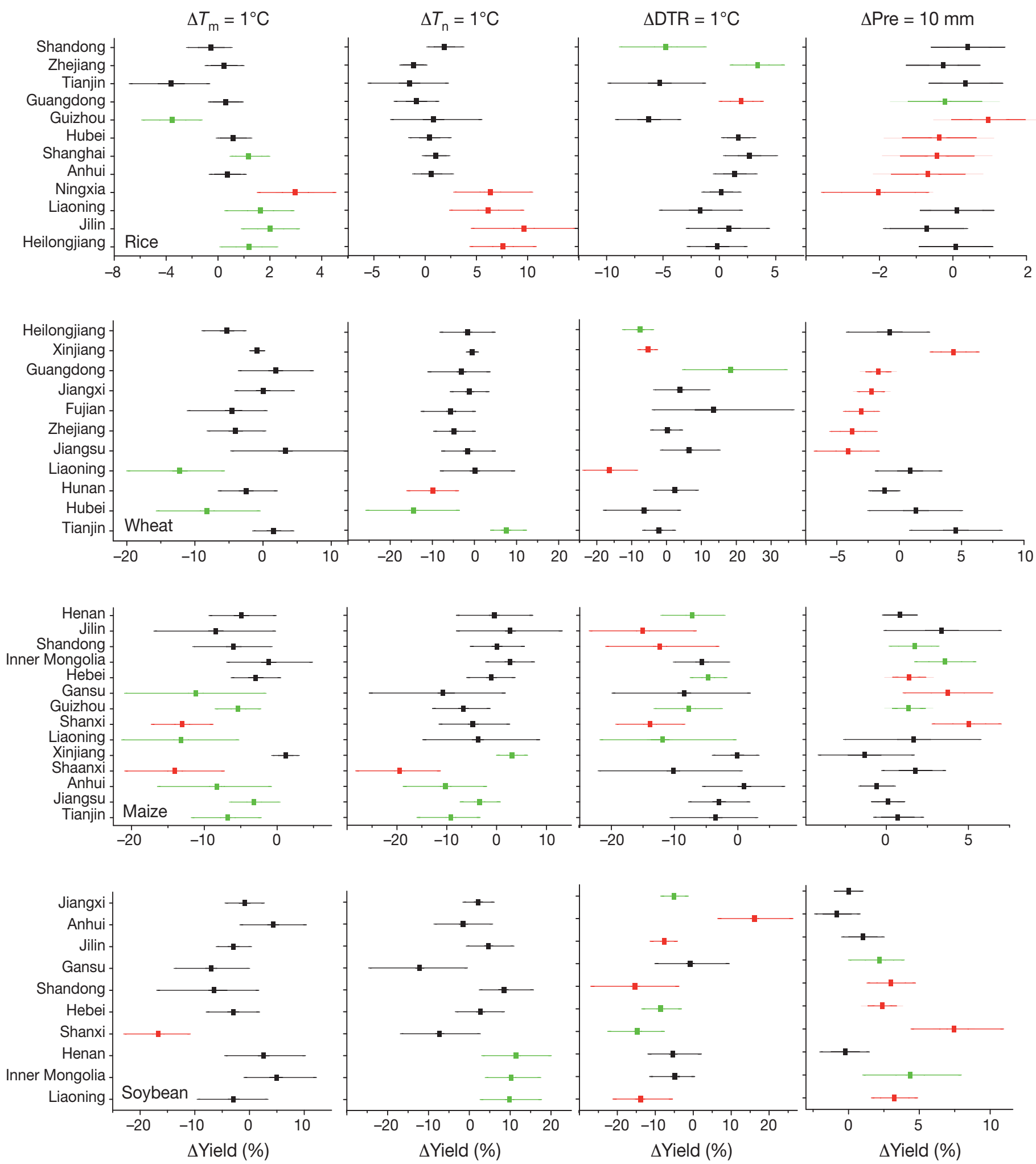

Fig. 3. Estimated coefficients for the response of $\Delta$ Yield (\% of the 2002 yield) to $\Delta T_{\mathrm{m}}, \Delta T_{\mathrm{n}}, \Delta \mathrm{DTR}$ and $\Delta$ Pre in a simple linear regression. Negative (positive) coefficients suggest the negative (positive) correlation between the 2 variables. Red: $p<0.01$; green: $\mathrm{p}<0.05$; black: $\mathrm{p}>0.05$. Error bars: $90 \%$ CI (5th to 95th percentile) based on bootstrap resampling of historical data with 1000 samples. Only provinces (autonomous region or municipality) where crop yield was significantly related to at least 1 of the 4 climate variables during the growing season are shown 
interannual rice yield changes in Ningxia was explained by growing season $T_{\mathrm{m}}$. The impacts of growing season $T_{\mathrm{n}}$ on rice yield were more pronounced. For example, rice yield significantly increased by 4.6 to $14.6 \%$ in Jilin and by 4.5 to $10.7 \%$ in Heilongjiang for each degree increase in growing season $T_{\mathrm{n}}$ (Fig. 3). Up to $29 \%$ of the variance in interannual rice yield changes in Heilongjiang was explained by growing season $T_{n}$.

The impacts of DTR on rice yield were negatively related to those of precipitation (Fig. 3) since DTR is often highly related to solar radiation (Bristow \& Campbell 1984), cloud cover and precipitation. DTR was negatively correlated to rice yield in Shandong, but positively related to rice yield in Guangdong and Zhejiang provinces (Fig. 3).

Growing season precipitation was negatively related to rice yield in Anhui (Fig. 2), Ningxia, Shanghai and Hubei (Fig. 3), possibly because frequent precipitation might have lead to insufficient solar radiation and insect infestation. This is in agreement with a previous report that continuous rainy weather during the growing season is unfavourable for rice production in southeast China (Tao \& Yokozawa 2005). In contrast, growing season precipitation was positively related to rice yield in the Guizhou and Guangdong provinces. Up to $24 \%$ of the variance in interannual rice yield changes in Anhui was explained by growing season precipitation.

\subsubsection{Wheat}

Among the 26 major provinces that produce wheat throughout China, Liaoning (Fig. 3) and Hubei provinces showed negative correlation between growing season $T_{\mathrm{m}}$ and wheat yield. Wheat yield significantly decreased by 5.9 to $19.8 \%$ in Liaoning and 0.6 to $15.4 \%$ in Hubei for each degree increase in growing season $T_{\mathrm{m}}$ (Fig. 3).

Growing season $T_{\mathrm{n}}$ was negatively related to wheat yield in Hubei ( $\mathrm{p}<$ $0.05)$ and Hunan $(\mathrm{p}<0.01)$ provinces (Fig. 4), but positively related to wheat
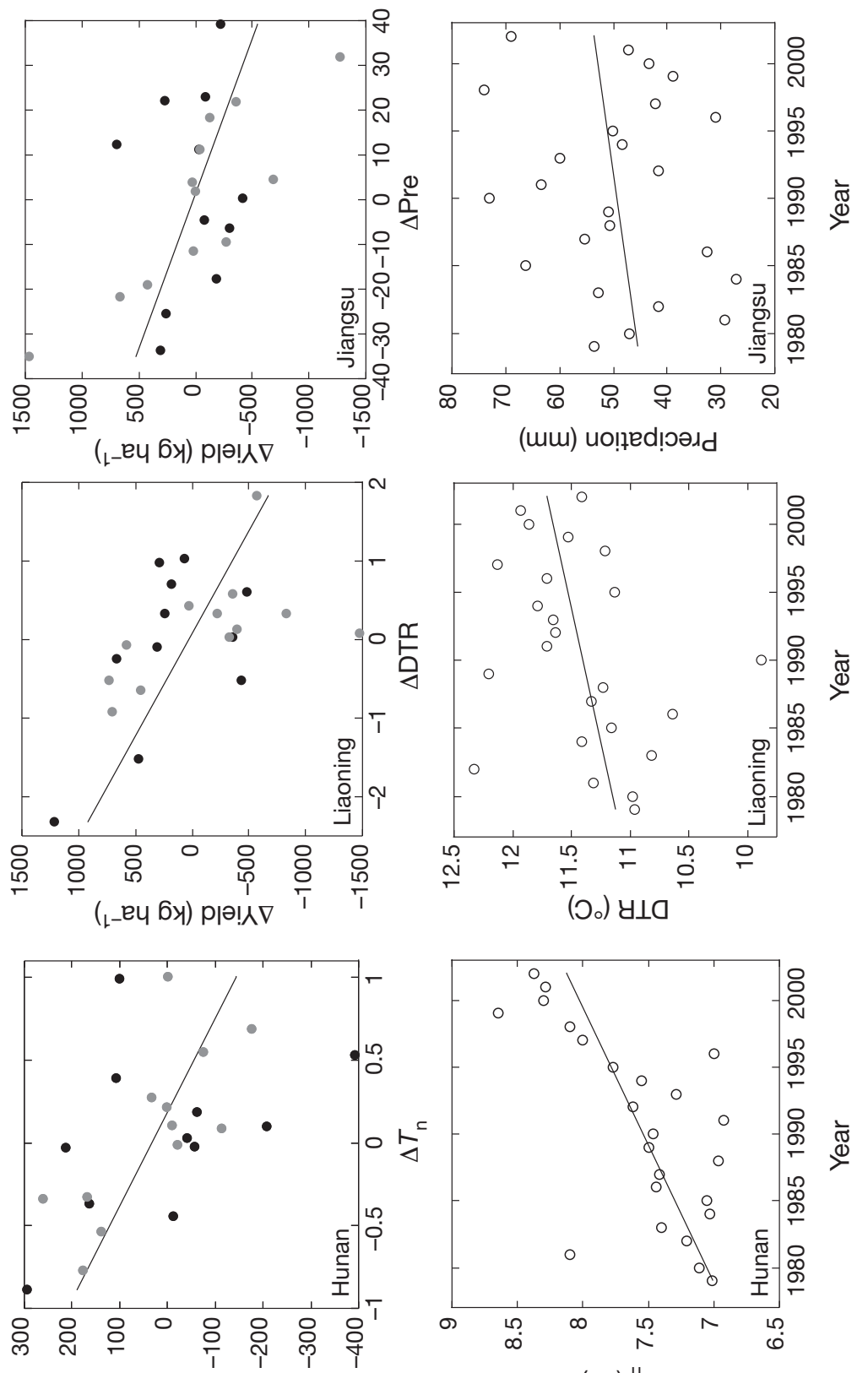

(„_еч бу) p|ə!ᄉ $\nabla$

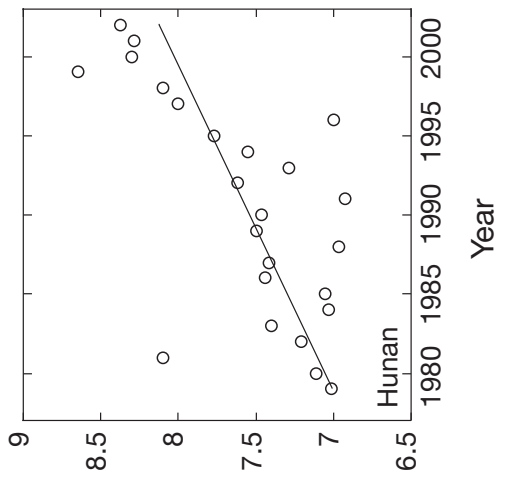

(ว。) ${ }^{\mathrm{u}} \perp$
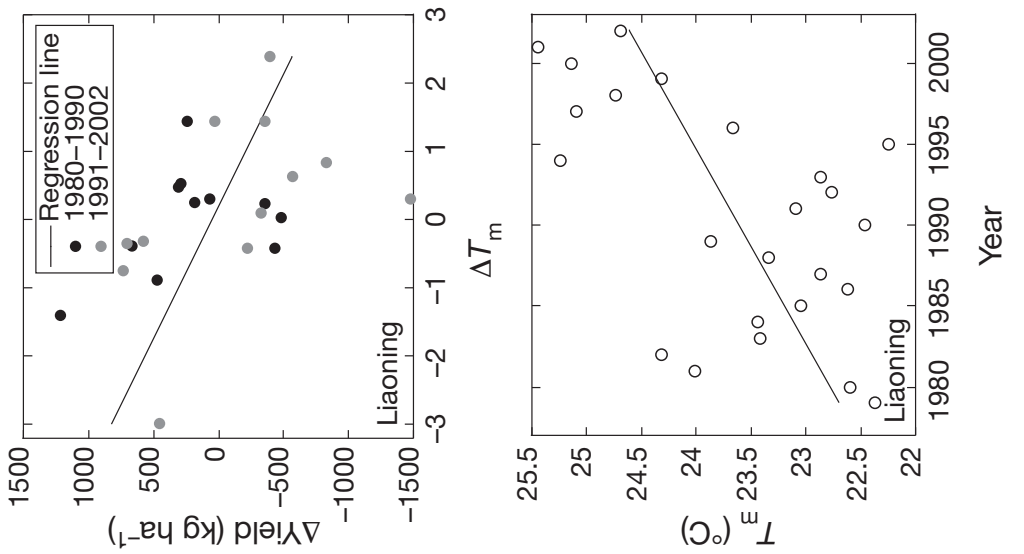

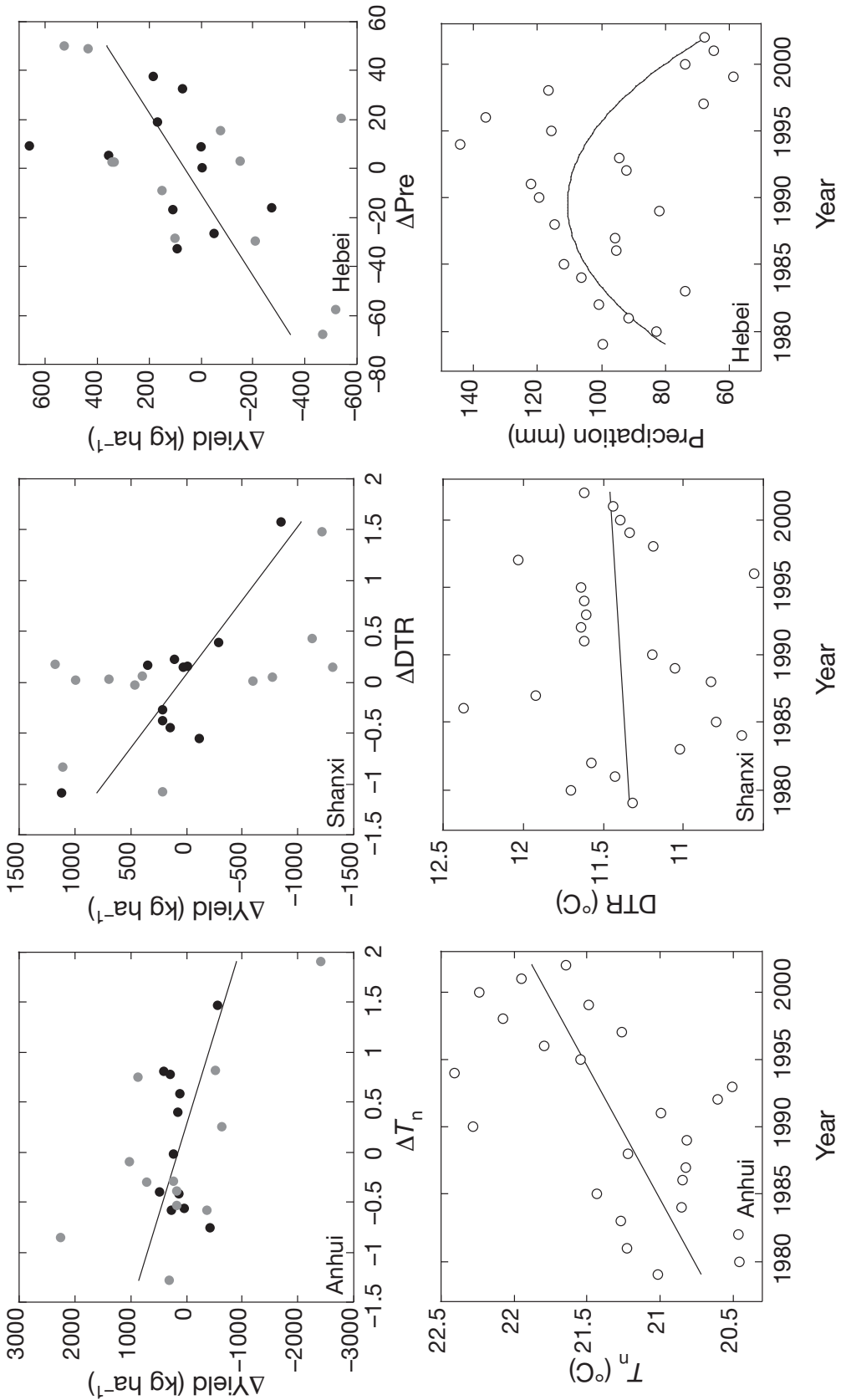

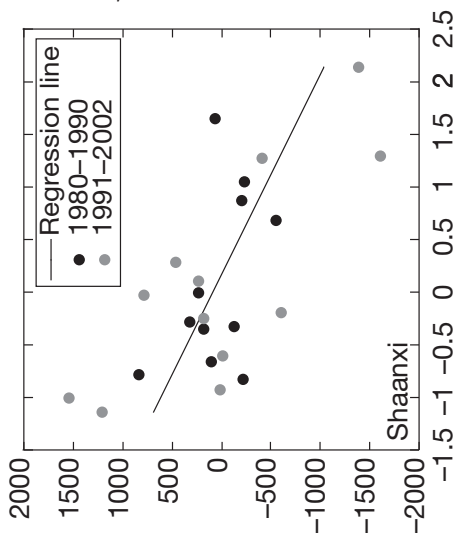

(„_еч бу) р|ә!ᄉ

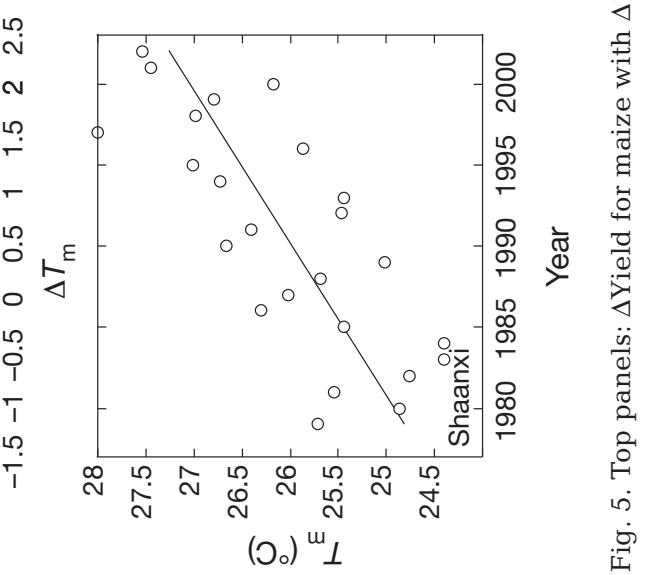

yield in Tianjin ( $\mathrm{p}<0.05)$ (Fig. 3). Wheat yield significantly decreased by 3.9 to $25.4 \%$ in Hubei province and by 4.2 to $15.7 \%$ in Hunan province for each degree increase in growing season $T_{n}$, but it increased significantly by 4.2 to $12.0 \%$ in Tianjin (Fig. 3).

DTR was negatively related to wheat yield in Heilongjiang and Liaoning (Fig. 4) in the northeast, and Xinjiang in the northwest, but was positively related to wheat yield in Guangdong province in the south (Fig. 3).

Growing season precipitation was negatively related to wheat yield in Jiangsu, Zhejiang, Fujian and Jiangxi in east China, and Guangdong in the south, where annual precipitation is $>1000 \mathrm{~mm}$. In contrast, wheat yield in Xinjiang in the northwest, where annual precipitation is $<500 \mathrm{~mm}$, was positively related to growing season precipitation (Fig. 3).

\subsubsection{Maize}

Compared to rice and wheat, maize yields were more sensitive to growing season climate in terms of area and amount of yield change (Fig. 3). Among the 22 major provinces that produce maize throughout China; Liaoning, Tianjin, Shanxi, Gansu, Shaanxi (Fig. 5), Anhui, Jiangsu and Guizhou (Fig. 3), showed negative relation between growing season $T_{\mathrm{m}}$ and maize yield. For example, maize yield significantly decreased by 7.4 to $20.7 \%$ in Shanxi, and by 2.4 to $8.3 \%$ in Guizhou for each degree increase in growing season $T_{\mathrm{m}}$ (Fig. 3).

Growing season $T_{\mathrm{n}}$ was negatively related to maize yield in Tianjin, Shanxi, Jiangsu, and Anhui (Fig. 5), but was positively related to maize yield in Xinjiang (Fig. 3). Maize yield significantly decreased by 11.6 to $27.9 \%$ in Shanxi and by 1.6 to $12.6 \%$ in Guizhou for each degree increase in growing season $T_{\mathrm{n}}$ (Fig. 3).

Growing season DTR was negatively related to maize yields in the major production areas Jilin, Liaoning, Shanxi (Fig. 5), Hebei, Shandong, 

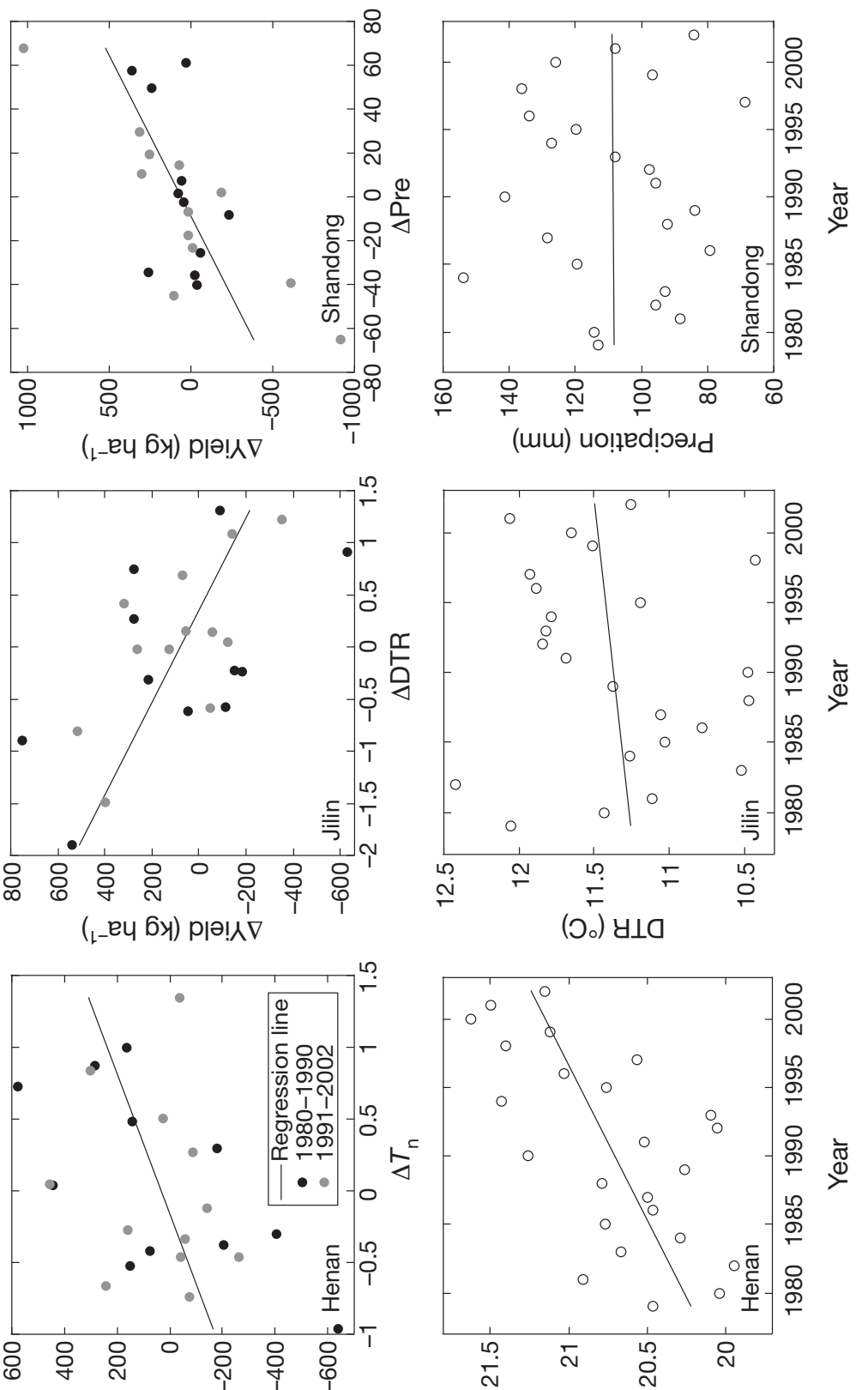

(„_еч 6у) ріә!ᄉ

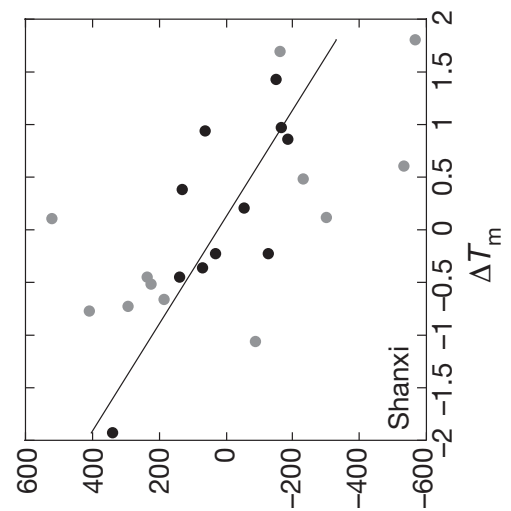

(__еч 6y) pрә!ᄉ $\nabla$

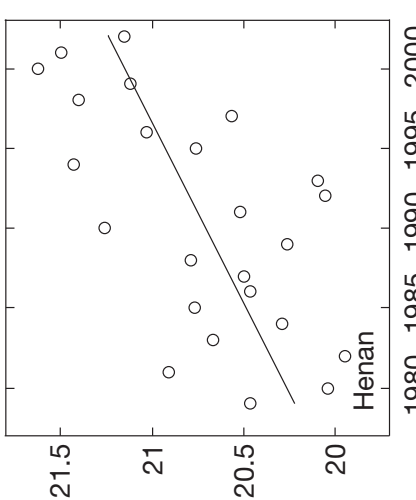

(อ。) ${ }^{\mathrm{u}} \perp$

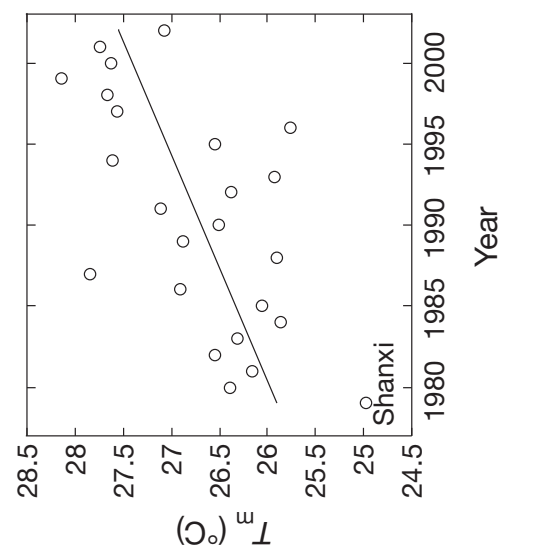

Henan and Guizhou (Fig. 3). The effects could be associated with water stress since growing season precipitation was significantly positively related to maize yields in most of these provinces.

\subsubsection{Soybean}

Among the 16 major provinces that produce soybean throughout China, Shanxi province (Fig. 6) showed negative relation between growing season $T_{\mathrm{m}}$ and soybean yield. Soybean yield significantly decreased by 11.1 to $22.7 \%$ in Shanxi for each degree increase in growing season $T_{\mathrm{m}}$ (Fig. 3).

Growing season $T_{\mathrm{n}}$ was positively related to soybean yield in Liaoning, Inner Mongolia and Henan province (Fig. 6). Soybean yield significantly increased by 3.0 to $17.3 \%$, and by 3.4 to $19.7 \%$ in Liaoning and Henan, respectively, for each degree increase in growing season $T_{\mathrm{n}}$ (Fig. 3).

DTR was negatively related to soybean yield in Jilin (Fig. 6), Liaoning, Shanxi, Hebei, Shandong and Jiangxi, but positively related to soybean yield in Anhui province (Fig. 3).

Growing season precipitation was positively related to soybean yield in Liaoning, Inner Mongolia, Gansu, Hebei, Shanxi (Fig. 3) and Shandong (Fig. 6), which is in the arid and semiarid climate zone. Up to $49 \%$ of the variance in interannual soybean yield changes in Hebei and Shandong could be explained by growing season precipitation.

\subsection{Recent climate trends and their impacts on crop yield and production}

In some of the provinces with significant crop-climate relationships, we found significant trends in the growing season climate (particularly $T_{\mathrm{n}}$ and $T_{\mathrm{m}}$ ) over the last few decades (Fig. 7). For example, during the period 1951-2002, rice growing season $T_{\mathrm{n}}$ had a significant trend in Heilongjiang, Jinlin, Liaoning, Anhui, Shanghai, Hubei, Guangdong and Zhejiang. Rice growing season DTR 

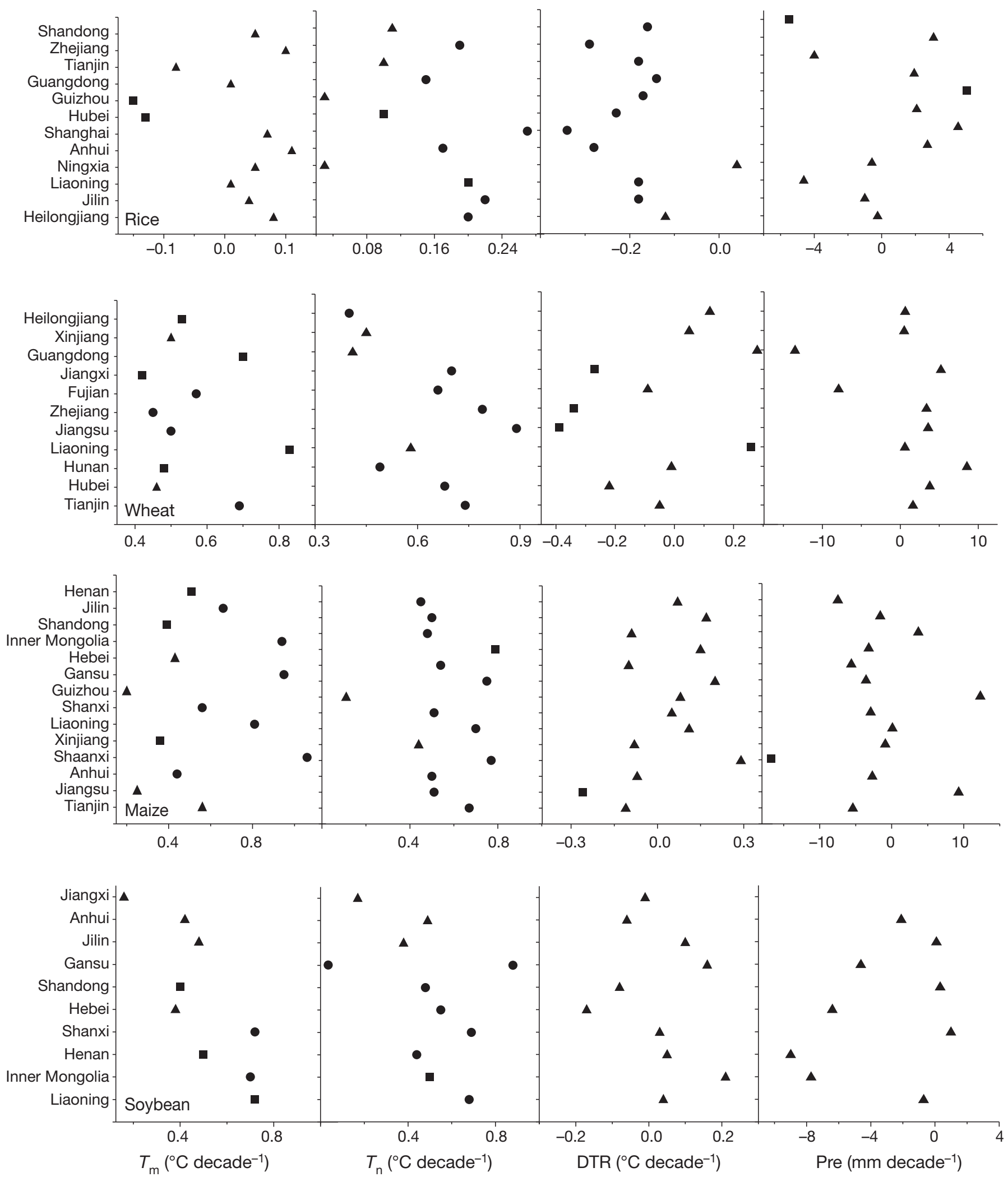

Fig. 7. Trends in climate variables during the crop growing season. $(\bullet) p<0.01$, (घ) $p<0.05$, and $(\boldsymbol{\bullet}) \mathrm{p}>0.05$. Only provinces (autonomous region or municipality) where crop yield was significantly related to at least 1 of the 4 climate variables during the growing season are shown 


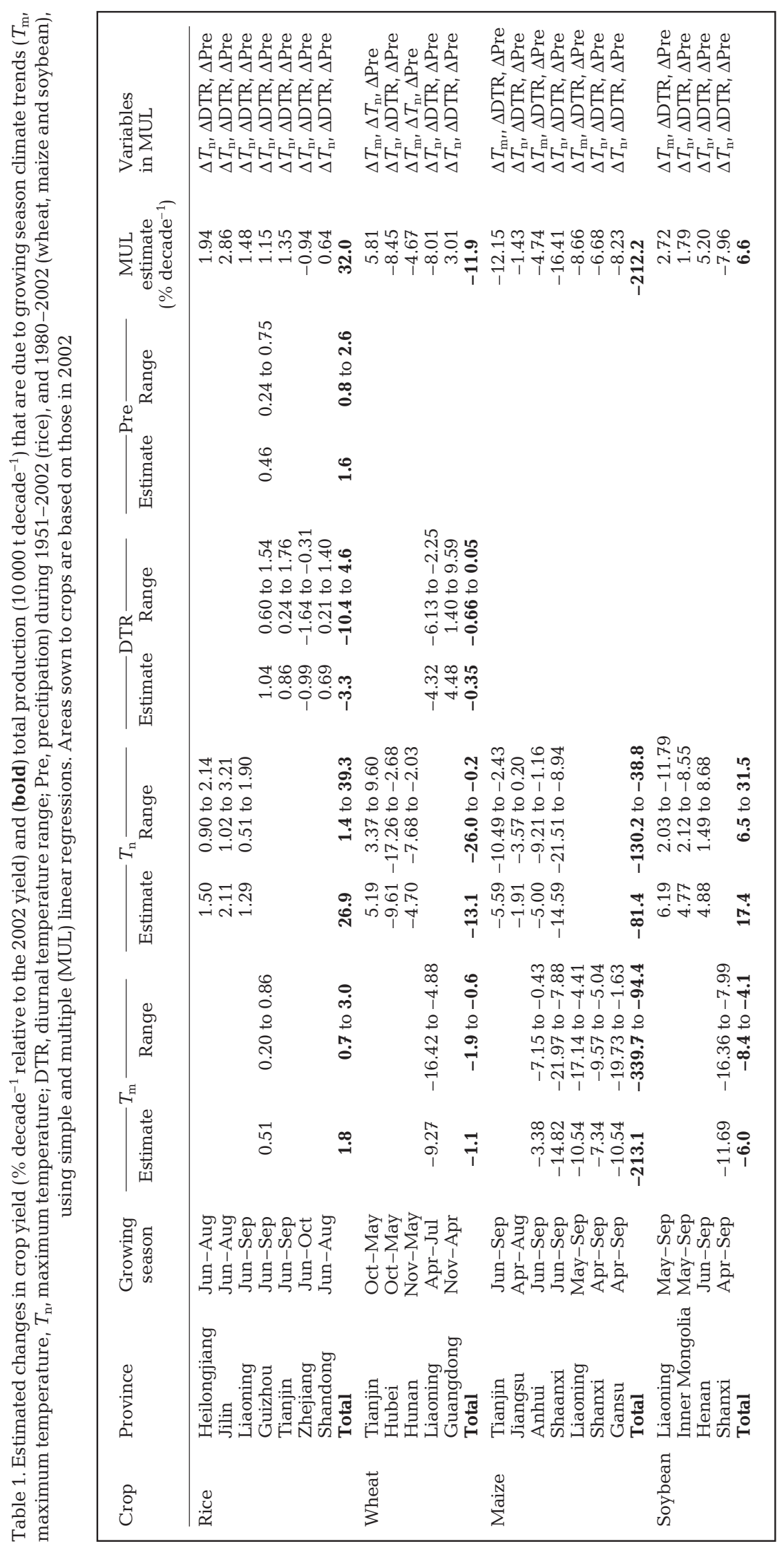

had a significant trend in Jinlin, Liaoning, Anhui, Shanghai, Hubei, Guizhou, Guangdong, Tianjin, Zhejiang and Shandong. During the period 1979-2002, $T_{\mathrm{n}}$ and $T_{\mathrm{m}}$ over the wheat growing season had significant trends in Tianjin, Hunan, Jiangsu, Zhejiang, Fijian, Jiangxi and Heilongjiang (Fig. 7). During the period 1951-2002, rice growing season $T_{\mathrm{n}}$ in Heilongjiang, Jilin and Liaoning provinces significantly increased by $0.20,0.22$ and $0.20^{\circ} \mathrm{C}$ decade $^{-1}$, respectively; rice growing season $T_{\mathrm{m}}$ and precipitation in Guizhou province decreased by $0.15^{\circ} \mathrm{C}$ decade $^{-1}$ and increased by $5.04 \mathrm{~mm}$ decade $^{-1}$, respectively (Fig. 7). Such significant trends in the climate variables possibly caused changes in crop yield and production over the last few decades.

In Table 1, we estimated the impacts of trends in climate variables on crop yield and production only in provinces where both climate-yield relationships and trends in the relevant climate variable were significant. For example, according to the climate trend (Fig. 7) and the yield response (Fig. 3), we estimated that during the period 1951-2002, rice yield could have increased (relative to the rice yield in 2002) by 1.50 , 2.11 and $1.29 \%$ decade $^{-1}$ due to the warming trend in growing season $T_{\mathrm{n}}$ in Heilongjiang, Jilin and Liaoning provinces, respectively; rice yield could have increased by 0.51 and $0.46 \%$ decade $^{-1}$ in Guizhou due to the cooling trend in $T_{\mathrm{m}}$ and increasing trend in precipitation, respectively. Rice yield could have increased by 1.04, 0.86 and $0.69 \%$ decade $^{-1}$ in Guizhou, Tianjin and Shandong, but could have decreased by $0.99 \%$ decade $^{-1}$ in Zhejiang province, relative to the rice yield in 2002, due to the decreasing trend in DTR (Table 1). Because the warming trend became more pronounced from the 1980s, our analysis from 1980 resulted in larger impacts for wheat, maize and soybean (Table 1). 
The trends in $T_{\mathrm{m}}$ and $T_{\mathrm{n}}$ over the last few decades increased rice yield in the northeast, and soybean in the north and northeast, but decreased maize yield in 7 provinces and wheat yield in Hubei, Hunan and Liaoning. Using the areas sown in 2002, we estimated that total rice production in China could have increased by $1.8 \times 10^{4}$ t (range $0.7 \times 10^{4}$ to $3.0 \times 10^{4}$ t) decade $^{-1}$ due to the trend in $T_{\mathrm{m}}$ during the period 1951-2002. It could have increased by $26.9 \times 10^{4} \mathrm{t}$ (range $1.4 \times 10^{4}$ to $39.3 \times 10^{4} \mathrm{t}$ ) decade ${ }^{-1}$ due to the trend in $T_{\mathrm{n}}$. In contrast, it could have decreased by $3.3 \times 10^{4} \mathrm{t} \mathrm{decade}^{-1}$ due to the trend in DTR (Table 1).

Based on estimates using the MUL method, which accounts for the impacts of the interaction of simultaneous changes in 3 climate parameters (Table 1), we estimated that rice yield could have increased in Heilongjiang, Jilin, Liaoning, Guizhou, Tianjin and Shandong. For example, rice yield would have increased by $1.94,2.86$ and $1.48 \%$ decade $^{-1}$ in Heilongjiang, Jilin and Liaoning provinces, respectively, relative to the rice yield in 2002, but decreased by $0.94 \%$ decade $^{-1}$ in Zhejiang province (Table 1). Total rice production in China could have increased by $32.0 \times 10^{4} \mathrm{t}$ decade $^{-1}$ due to the trend in growing season climate during the period 1951-2002 (Table 1). Wheat yield could have increased in Tianjin and Guangdong, but decreased in Hubei, Hunan and Liaoning; total production of wheat, maize and soybean in China could have changed by $-11.9 \times 10^{4},-212.2 \times 10^{4}$ and $6.6 \times$ $10^{4} \mathrm{t} \mathrm{decade}^{-1}$, respectively, due to the trend in growing season climate during the period 1979-2002 (Table 1).

\section{DISCUSSION}

\subsection{Response patterns and mechanisms}

Our analysis presents the general response patterns of regional agricultural productivity to seasonal climate variability and change; however, the response mechanisms need to be further investigated. Some physiological mechanisms by which $T_{\mathrm{m}}, T_{\mathrm{n}}$ and DTR may affect crop yields have been partly revealed for rice (Matsui \& Horie 1992, Tao et al. 2006, Tao et al. 2008), wheat (Metho et al. 1999), maize (Muchow 1990, Schoper et al. 1986) and soybean (Koti et al. 2007). Higher temperatures may accelerate crop development and reduce grain filling duration, while temperature extremes during flowering can reduce grain or seed number (e.g. Matsui \& Horie 1992). Crop responses to a change in temperature depend on the temperature optima of photosynthesis, growth and yield, all of which may differ for different crops (Conroy et al. 1994). When temperature is below the optimum for photosynthesis, a small increase in temperature can greatly stimulate crop growth. The converse is true when temperature is near the maximum for yield. A small increase in temperature can dramatically reduce yield (Baker \& Allen 1993). Climate warming may have beneficial or harmful impacts on crop production in high or low latitude regions depending on whether the current temperature is generally less or more than the optimal temperature $\left(T_{\mathrm{o}}\right)$ for crop production (IPCC 2001). This mechanism underlies crop response patterns to temperature change in our study. For example, our analysis showed that in Heilongjiang, Jilin and Liaoning provinces, detrended rice yield showed a positively linear relationship with growing season mean temperature, suggesting that the current growing season mean temperature in these provinces is $<T_{0}$, and that a warming trend could increase rice yield. In contrast, in Guizhou province, detrended rice yield showed a negatively linear relationship with growing season mean temperature, suggesting that the current growing season mean temperature is at or above $T_{0}$, and that a warming trend could reduce rice yield.

The impacts of DTR were bilateral, as shown in Fig. 3. An increase in DTR may reduce yield because the associated increase in $T_{\mathrm{m}}$ results in increased water stress or reductions in net photosynthetic rates (Dhakhwa \& Campbell 1998, Tao et al. 2006), but may benefit yields in cases when development or grain filling rates are more sensitive to $T_{\mathrm{n}}$ than $T_{\mathrm{m}}$ (Wilkens \& Singh 2001). At country scale, Lobell (2007) showed that rice and maize yields in China diminished with increased DTR during the period 1961-2002, while DTR effects on wheat yield were insignificant. Our results showed DTR to be significantly and generally negatively related to crop (particularly maize and soybean) yield variability. Since ongoing climate change is characterized by a marked asymmetry between maxima and minima, with $T_{\mathrm{n}}$ rising faster than $T_{\mathrm{m}}$, and many climate models project further significant changes in DTR, effects of DTR on crops may be important to consider in impact and adaptation studies (Rosenzweig \& Tubiello 1996, Tubiello et al. 2002, Lobell 2007).

Growing season precipitation had a significant negative relation to rice and wheat yield in south China, but significant positive relation to maize and soybean yield in the north and northeast (Fig. 3). These results are quite consistent with the actual status over the last few decades. In south China where the climate is humid and annual precipitation is generally $>1000 \mathrm{~mm}$, too much precipitation often occurred during the wheat grain filling period, which could lead to yield losses from disease and root problems. Moreover, too much precipitation often occurred during the rice 
heading period, which could lead to yield losses from disease, insects and insufficient solar radiation (Tao \& Yokozawa 2005). In the north and northeast China where the climate is arid and semi-arid, and annual precipitation is generally $<600 \mathrm{~mm}$, water stress is the most crucial limiting factor for rainfed crop yields (Tao et al. 2003).

Changes in crop yields are eventually subjected to the combined impacts of multiple climate variables. While simple linear regression can clearly distinguish the response of crop yield to the most relevant climate variables, the MUL method can, to some extent, estimate the combined impacts of several relevant climate variables. The crop yield change estimated by MUL could be more or less than the estimate based on a single climate variable (Table 1) depending on the relative impacts of the different climate variables used and their trends.

\subsection{Impacts of climate variability and trends}

Several reports have shown that the recent warming trend has had discernible impacts on crop development and production (e.g. Nicholls 1997, Lobell \& Asner 2003, Chmielewski et al. 2004, Peng et al. 2004, Tao et al. 2006). Our analysis also showed discernible impacts on crop production even on a provincial scale. Across provinces and crops, the trends in $T_{\mathrm{n}}$ (Fig. 7) and their impacts were more pronounced than those of $T_{\mathrm{m}}$ for rice, wheat and soybean (Fig. 3, Table 1).

The yields of the 4 major crops were also significantly related to growing season precipitation in some provinces (Fig. 3), suggesting that the interannual variability in crop yield due to variability in precipitation is quite large (Tao et al. 2004). However, the trends in seasonal precipitation over the last few decades were insignificant in most of the provinces (Fig. 7). As a result, the impacts of precipitation trends on crop yields over the last few decades were generally insignificant (Table 1).

Likewise, our results showed that the DTR trend could have reduced rice yield in Zhejiang by $66.0 \mathrm{~kg}$ $\mathrm{ha}^{-1}$ decade $^{-1}$, but increased rice yield in Tianjin, Guizhou and Shandong; the DTR trend could have reduced wheat yield in Liaoning by $99.8 \mathrm{~kg} \mathrm{ha}^{-1}$ decade $^{-1}$, but increased wheat yield in Guangdong by $133.9 \mathrm{~kg} \mathrm{ha}^{-1}$ decade $^{-1}$. The impacts of DTR trends on maize and soybean yield were insignificant (Table 1). The interannual variability in DTR significantly correlated with maize and soybean yield in the major production regions (Fig. 3), but the trend in DTR since 1980 was generally insignificant (Fig. 7). The impacts of DTR on crop yield and production could become significant if longer time series were available, such as those for rice.

\subsection{Uncertainties}

Compared with the observed data at experimental stations, uncertainties in the statistical dataset for crop production and the regional climate dataset could be larger. Nevertheless, extensive studies have demonstrated that such datasets are good enough to investigate the climate-yield relationships and climate trends, at least on a large scale (e.g. Lobell 2007, Lobell \& Field 2007, Lobell et al. 2008). The statistical datasets on crop productivity did not separate irrigated from rainfed production, which, among other things, could weaken the relationship between precipitation and crop yield for paddy rice or in provinces with high irrigation proportion. Nevertheless, the statistical data can generally capture the trend and interannual variability in crop productivity due to technology development and meteorological disasters at provincial to national scales.

Results could also depend on the length of the study period (as shown above), and agricultural management practices. The analysis was based on the assumption that the impacts of agricultural management practices on crop yields did not change with yearly climate and crop growing conditions. If farmers adapted their management practices to yearly climate and crop growing conditions, the estimated beneficial impacts from climate variables may be exaggerated, while the estimated harmful impacts may be underestimated.

\section{CONCLUSIONS}

Our analysis showed that the yields of major crops were significantly related to growing season climate in the main production regions of China over the last few decades. Furthermore, the growing season temperature, especially $T_{n}$, had a significant warming trend. Such a climate trend has affected regional agricultural productivity. Among the 4 major crops, maize was the most vulnerable to the trends in both $T_{\mathrm{m}}$ and $T_{\mathrm{n}}$. Rice, wheat and soybean were affected more by $T_{\mathrm{n}}$ than by $T_{\mathrm{m}}$. The changes in crop yield for each degree change in $T_{\mathrm{m}}$ or $T_{\mathrm{n}}$ generally ranged from -18.9 to $11 \%(90 \%$ CI of -22.7 to $19.7 \%$ ), which were crop- and regiondependent.

Although precipitation and DTR were also significantly related to crop yields, the trends in growing season precipitation and DTR (since 1980) were generally insignificant.

In this study, we presented the general spatial patterns of climate-yield relationships, climate trends and the impacts of recent climate trends using statistical methods. However, the key response mechanisms of 
different crops to local seasonal climate change (variability) need further investigation to better understand the response patterns and predict the consequences of climate change and variability on regional agricultural production.

Acknowledgements. This study was supported by the Innovative Program of Climate Change Projection for the 21st Century (KAKUSHIN Program), Japan. F.T. acknowledges the support of the 'Hundred Talents' Program of the Chinese Academy of Sciences. We thank the 2 anonymous reviewers and the editor for their insightful comments.

\section{LITERATURE CITED}

Baker JT, Allen LH (1993) Contrasting crop species responses to $\mathrm{CO}_{2}$ and temperature: rice, soybean and citrus. Vegetatio 104-105:239-260

Bristow KL, Campbell GS (1984) On the relationship between incoming solar radiation and daily maximum and minimum temperature. Agric For Meteorol 31:159-166

CCSA (The Compiling Committee of State Atlas) (ed) (1989) The agricultural atlas of China. Cartographic Publishing House of China, Beijing, p 34-93

Chmielewski FM, Muller A, Bruns E (2004) Climate changes and trends in phenology of fruit trees and field crops in Germany, 1961-2000. Agric For Meteorol 121:69-78

Conroy JP, Seneweera S, Basra AS, Rogers G, Nissen-Wooller $\mathrm{B}$ (1994) Influence of rising atmospheric $\mathrm{CO}_{2}$ concentrations and temperature on growth, yield and grain quality of cereal crops. Aust J Plant Physiol 21:741-758

Dhakhwa GB, Campbell CL (1998) Potential effects of differential day-night warming in global climate change on crop production. Clim Change 40:647-667

Frolking S, Qiu J, Boles S, Xiao X, Liu J, Zhuang Y, Li C, Qin $X$ (2002) Combining remote sensing and ground census data to develop new maps of the distribution of rice agriculture in China. Global Biogeochem Cycles 16:1091. doi: 10.1029/2001GB001425

Iglesias A, Quiroga S (2007) Measuring the risk of climate variability to cereal production at five sites in Spain. Clim Res 34:47-57

IPCC (2001) Climate change 2001: impacts, adaptation, and vulnerability. Contribution of Working Group II to the 3rd Assessment Report of the Intergovernmental Panel of Climate Change. Cambridge University Press, Cambridge

> Jones GV, Goodrich GB (2008) Influence of climate variability on wine regions in the western USA and on wine quality in the Napa Valley. Clim Res 35:241-254

Koti S, Raja Reddy K, Kakani VG, Zhao D, Gao W (2007) Effects of carbon dioxide, temperature and ultraviolet-B radiation and their interactions on soybean (Glycine max L.) growth and development. Environ Exp Bot 60:1-10

Lobell DB (2007) Changes in diurnal temperature range and national cereal yields. Agric For Meteorol 145:229-238

Lobell DB, Asner GP (2003) Climate and management contributions to recent trends in US agricultural yields. Science 299:1032

Lobell DB, Field CB (2007) Global scale climate-crop yield relationships and the impacts of recent warming. Environ Res Lett 2:014002. doi:10.1088/1748-9326/2/1/014002
Lobell DB, Burke MB, Tebaldi C, Mastrandrea MD, Falcon WP, Naylor RL (2008) Prioritizing climate change adaptation needs for food security in 2030. Science 319:607-610

Matsui T, Horie T (1992) Effect of elevated $\mathrm{CO}_{2}$ and high temperature on growth and yield of rice. II. Sensitivity period and pollen germination rate in high temperature sterility of rice spikelets at flowering. Jpn J Crop Sci 61:148-149

Metho LA, Hammes PS, Groeneveld HT, Beyers EA (1999) Effects of photoperiod and temperature on grain yield, grain number, mean kernel mass and grain protein content of vernalized and unvernalized wheat (Triticum aestivum L.). Biotronics 28:55-71

Mitchell TD, Jones PD (2005) An improved method of constructing a database of monthly climate observations and associated high-resolution grids. Int J Climatol 25:693-712

> Muchow RC (1990) Effect of high temperature on graingrowth in field-grown maize. Field Crops Res 23:145-158

> Nicholls N (1997) Increased Australian wheat yield due to recent climate trends. Nature 387:484-485

> Peng S, Huang J, Sheehy JE, Laza RC and 5 others (2004) Rice yields decline with higher night temperature from global warming. Proc Natl Acad Sci USA 101:9971-9975

> Qiu J, Tang H, Frolking S, Boles S and 5 others (2003) Mapping single-, double-, and triple-crop agriculture in China at $0.5^{\circ} \times 0.5^{\circ}$ by combining county-scale census data with a remote sensing-derived land cover map. Geocarto Int 18: $3-13$

- Rosenzweig C, Parry ML (1994) Potential impact of climate change on world food supply. Nature 367:133-138

> Rosenzweig C, Tubiello FN (1996) Effects of changes in minimum and maximum temperature on wheat yields in the central US: a simulation study. Agric For Meteorol 80: $215-230$

Schoper JB, Lambert RJ, Vasilas BL (1986) Maize pollen viability and ear receptivity under water and high temperature stress. Crop Sci 26:1029-1033

Tao F, Yokozawa M (2005) Risk analyses of rice yield to seasonal climate variability in China. Jpn J Agric Meteorol 60:885-887

Tao F, Yokozawa M, Hayashi Y, Lin E (2003) Changes in agricultural water demands and soil moisture in China over the last half-century and their effects on agricultural production. Agric For Meteorol 118:251-261

Tao F, Yokozawa M, Zhang Z, Hayashi Y, Grassl H, Fu C (2004) Variability in climatology and agricultural production variability in China in association with East Asian monsoon and El Niño Southern Oscillation. Clim Res 28: 23-30

Tao F, Yokozawa M, Xu Y, Hayashi Y, Zhang Z (2006) Climate changes and trends in phenology and yields of field crops in China, 1981-2000. Agric For Meteorol 138:82-92

> Tao F, Hayashi Y, Zhang Z, Sakamoto T, Yokozawa M (2008) Global warming, rice production and water use in China: developing a probabilistic assessment. Agric For Meteorol 148:94-110

- Tubiello FN, Rosenzweig C, Goldberg RA, Jagtap S, Jones JW (2002) Effects of climate change on US crop production: simulation results using two different GCM scenarios. Part I. Wheat, potato, maize, and citrus. Clim Res 20: 259-270

Wilkens P, Singh U (2001) A code-level analysis for temperature effects in the CERES models. In: White J (ed) Modeling temperature response in wheat and maize. CIMMYT, El Batan, p 1-7

Submitted: April 23, 2008; Accepted: July 31, 2008 Proofs received from author(s): November 17, 2008 